\title{
Study on Corrosion of Macroporous Silicon in Sodium Hydroxide Solution by Electrochemical Methods and Scanning Electron Microscopy
}

\author{
Chuan Lai, ${ }^{1,2,3}$ Zhen Xiang, ${ }^{2,4}$ Changlu Liu, ${ }^{1}$ Chaoju Zhu, ${ }^{1}$ Hui Wang, ${ }^{1}$ and Hui Zhu ${ }^{1}$ \\ ${ }^{1}$ School of Chemistry and Chemical Engineering, Sichuan University of Arts and Science, Dazhou 635000, China \\ ${ }^{2}$ Key Laboratory of Green Catalysis of Sichuan Institutes of Higher Education, Sichuan University of Science and Engineering, \\ Zigong 643000, China \\ ${ }^{3}$ Material Corrosion and Protection Key Laboratory of Sichuan Province, Sichuan University of Science and Engineering, \\ Zigong 643000, China \\ ${ }^{4}$ School of Chemistry and Pharmaceutical Engineering, Sichuan University of Science and Engineering, Zigong 643000, China
}

Correspondence should be addressed to Zhen Xiang; tougaolc@163.com

Received 24 June 2015; Accepted 19 August 2015

Academic Editor: Michael J. Schütze

Copyright (C) 2015 Chuan Lai et al. This is an open access article distributed under the Creative Commons Attribution License, which permits unrestricted use, distribution, and reproduction in any medium, provided the original work is properly cited.

The fabricated macroporous silicon with a porosity of $26.33 \%$ corrosion in $\mathrm{NaOH}$ solution was systemically investigated by open circuit potential measurements, linear polarization measurements, potentiodynamic polarization measurements, and scanning electron microscopy, respectively. Results show that the potential open circuit and linear polarization resistance decreases with the $\mathrm{NaOH}$ concentration increasing. The corrosion potential shifts significantly to more negative potentials and corrosion current density increases with $\mathrm{NaOH}$ concentration increasing. Adding ethanol to $1.0 \mathrm{M} \mathrm{NaOH}$ can lead to the linear polarization resistance decrease, corrosion potentials shift in the positive direction, and corrosion current density increase. In addition, the scanning electron microscopy images demonstrate that the macroporous silicon samples are seriously damaged by $1.0 \mathrm{M} \mathrm{NaOH}$ and $1.0 \mathrm{M}$ $\mathrm{NaOH} / \mathrm{EtOH}(30 \%)$.

\section{Introduction}

Porous silicon (PS), formed on the surface of crystalline silicon substrates by electrochemical anodization in hydrofluoric acid, was firstly observed by Uhlir in 1956 at the Bell Labs during the investigation of electrochemical methods for polishing germanium and silicon wafers [1]. Owing to the various potential applications in electronics and optoelectronics fields, the striking photoluminescence properties of PS at room temperature have attracted considerable research interest since their discovery in 1990 by Canham [2]. Over the past two decades, the fabrication methods, morphologies, microstructures, and optoelectronic properties of PS have been improved enormously.

At present, with numerous unique features, such as the high specific surface area, convenient surface chemistry, significant optical properties and electronic properties, biocompatibility, biodegradability, bioresorbability, and low toxicity, the PS has been applied in electronics, photonics, and biosensing [3-7] and used as an insulating layer in the siliconon-insulator applications, a sensing layer in biosensors or chemical sensors, an energy carrier, and a sacrificial layer in micromachining, as an important material for solar cell, and as an excellent biomaterial in tissue engineering, tumor imaging, and bioreactor platform drug delivery [8-13].

However, there are few works focusing on researching about the applications of PS in alkaline solutions resulting from the dissolution/corrosion of PS in these solutions [1417]. According to our previous works [18-20], although the corrosion of PS in $\mathrm{NaOH}, \mathrm{KOH}$, and $\left(\mathrm{CH}_{3}\right)_{4} \mathrm{NOH}$ was studied by weight loss measurements, there are few works focusing on the investigation of PS corrosion in alkaline solutions using open circuit potential measurements, linear polarization measurements, and potentiodynamic polarization measurements. 
Considering the importance of electrochemical parameters of PS corrosion in alkaline solutions, the aim of the present work is to report the corrosion behavior of macroporous silicon in $\mathrm{NaOH}$ solution by electrochemical methods. Firstly, several macroporous silicon samples were fabricated. Then, the corrosion behavior of macroporous silicon in $\mathrm{NaOH}$ solution without and with ethanol (EtOH) was systemically studied using open circuit potential measurements, linear polarization measurements, potentiodynamic polarization measurements, and scanning electron microscopy.

\section{Experimental Details}

2.1. Reagents and Materials. Hydrofluoric acid (40\%, A. R., $\mathrm{HF}$ ), ethanol (99.5\%, A. R., EtOH), acetone (A. R.), and sodium hydroxide (A. R., $\mathrm{NaOH}$ ) were purchased from Sinopharm Chemical Reagent Co., Ltd. All the reagents were commercially available and used without further purification. The silicon substrate of silicon wafers was purchased from Emei Semiconductor Material Institute (China), which was a phosphorus doped n-type wafer with a resistivity of 2$4 \Omega \mathrm{cm}, 500-550 \mu \mathrm{m}$ thick and (100) oriented.

2.2. Preparation of Macroporous Silicon. Porous silicon (PS) samples were fabricated by electrochemical anodization of $\mathrm{n}$ type silicon wafers in the etching solution of $\mathrm{HF}(40 \%)$ : $\mathrm{EtOH}$ $(99.5 \%)=1: 1$ at a current density of $30 \mathrm{~mA} \mathrm{~cm}^{-2}$ for $30 \mathrm{~min}$ [21-23]. Anodization process was performed in a Teflon cell by using two-electrode configuration with $\mathrm{Pt}$ gauze as the cathode and silicon substrate as the anode. Meanwhile, the etching process was illuminated by a $150 \mathrm{~W}$ high pressure mercury lamp at a distance of $20 \mathrm{~cm}$. After being prepared, the fresh PS samples were rinsed with double distilled water and ethanol. The most accepted model for describing etching mechanism for formation of PS has been proposed by Lehmann and Gösele [24]; in this model, the reaction of silicon etching to prepare PS is given in (1) [24, 25], where $\mathrm{h}^{+}$ and $\mathrm{e}^{-}$represent hole and electron, respectively. Hence,

$$
\mathrm{Si}+6 \mathrm{HF}+2 \mathrm{~h}^{+} \longrightarrow \mathrm{H}_{2}+\mathrm{SiF}_{6}{ }^{2-}+4 \mathrm{H}^{+}+\mathrm{e}^{-}
$$

Based on the size of pore diameters, the fabricated PS can be divided into microporous silicon $(\leq 2 \mathrm{~nm})$, mesoporous silicon $(2-50 \mathrm{~nm})$, and macroporous silicon $(>50 \mathrm{~nm})$. According to the scanning electron microscopy analysis in Section 3.5, because of the pore diameter more than $50 \mathrm{~nm}$, the prepared PS turns out to be macroporous silicon. Meanwhile, the porosity and thickness of macroporous silicon were estimated by weight loss measurements [26] using the optimized corrosion solution to completely rapidly remove the PS layer from PS samples [26]. The porosity and thickness of the prepared macroporous silicon are $26.33 \%$ and $144.10 \mu \mathrm{m}$, respectively.

\subsection{Electrochemical Measurements. Electrochemical mea-} surements were carried out by a conventional three-electrode cell that consisted of the macroporous silicon working electrode $\left(0.95 \mathrm{~cm}^{2}\right)$, a platinum gauze counter electrode, and a silver-silver chloride $(\mathrm{Ag} / \mathrm{AgCl})$ electrode as a reference

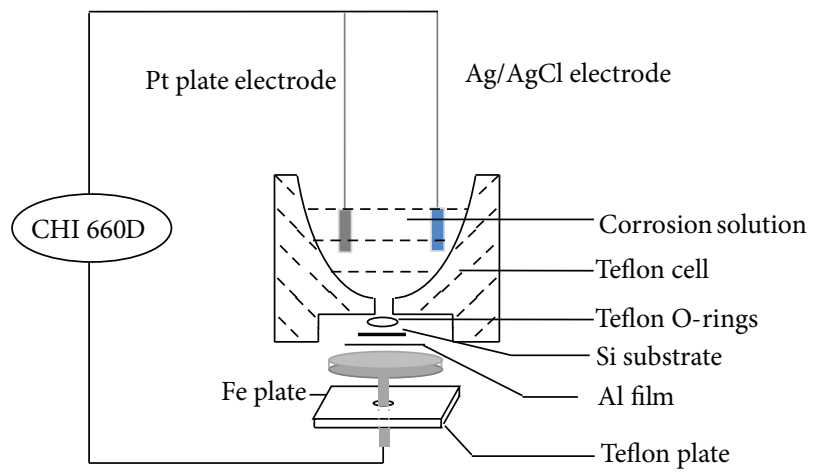

FIGURE 1: Schematic diagram of the experimental setup for studying the corrosion of macroporous silicon in $\mathrm{NaOH}$ solution by electrochemical methods.

electrode. The open circuit potential, linear polarization, and potentiodynamic polarization measurements were carried out using a computer to control CHI 660D Electrochemical Workstation (China) for investigating the electrochemical behavior of macroporous silicon in $\mathrm{NaOH}$ solution. According to our previous work [27], the whole schematic diagram of experimental setup for electrochemical measurements was shown in Figure 1.

It is generally required to stabilize the open circuit potential before running the linear polarization and potentiodynamic polarization measurements. Before measurements, the electrode was allowed to corrode freely and its open circuit potential was recorded as a function of time for 800 s. After this time a steady-state open circuit potential corresponding to the corrosion potential of the working electrode was obtained. As for linear polarization measurements, the potential of the electrode was scanned from $-20 \mathrm{mV}$ to $+20 \mathrm{mV}$ versus corrosion potential at scan rate of $0.166 \mathrm{mV} \mathrm{s}^{-1}$ and the polarization resistance was calculated from the slope of potential versus current curve in the vicinity of corrosion potential. Tafel polarization curves were obtained in the potential range of $-800 \mathrm{mV}$ to $+800 \mathrm{mV}$ in regard to open circuit potential. The corrosion current densities were estimated by extrapolation of the anodic and cathodic Tafel lines.

In this study, it should be noted that the electrochemical corrosion behavior of macroporous silicon in $1.0 \mathrm{M} \mathrm{NaOH}$ was investigated at a relative lower temperature of $291 \mathrm{~K}$ due to the existence of plenty of bubbles formed from the macroporous silicon in $1.0 \mathrm{M} \mathrm{NaOH}$ at the relative higher temperature, which would affect the accuracy of electrochemical measurements.

2.4. Scanning Electron Microscopy. The morphology images of macroporous silicon before and after electrochemical measurements in $1.0 \mathrm{M} \mathrm{NaOH}$ without and with $30 \%$ ethanol at $291 \mathrm{~K}$ were observed by scanning electron microscopy (SEM, JEOL JSM-6510).

\section{Results and Discussion}

3.1. Dissolution Chemistry. It is well known that different Si$\mathrm{Si}$ bonds and various kinds of activated $\mathrm{Si}-\mathrm{H}$ bonds present 


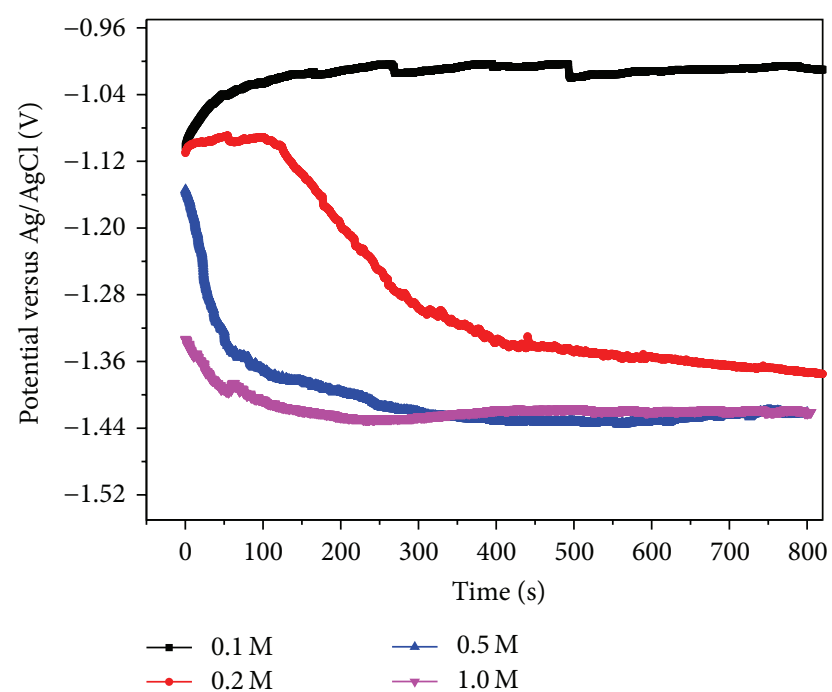

FIGURE 2: Open circuit potential-time curves of macroporous silicon corrosion in different concentrations of $\mathrm{NaOH}$ solution.

on macroporous silicon layer [20, 26-28]. Meanwhile, both the macroporous silicon layer $\left(\mathrm{Si}_{x} \mathrm{SiH}_{y}(x+y=4)\right)$ and silicon substrate $(\mathrm{Si}$ ) can react with $\mathrm{NaOH}$ solution to form hydrogen gas $\left(\mathrm{H}_{2}\right)$, which can be illustrated by $(2)[20,26,29,30]$. The essence of corrosion/dissolution of macroporous silicon in $\mathrm{NaOH}$ solution is the reaction among macroporous silicon layer with various $\mathrm{Si}-\mathrm{H}$ bonds, silicon substrate $(\mathrm{Si})$ with different $\mathrm{Si}-\mathrm{Si}$ bonds, and aqueous $\mathrm{NaOH}$.

3.2. Open Circuit Potential Measurements. The open circuit potential-time curves of macroporous silicon corrosion in different concentrations of $\mathrm{NaOH}$ solution at $291 \mathrm{~K}$ are shown in Figure 2. It is evident from the graph that the increase of $\mathrm{NaOH}$ concentration finally caused a shift in the direction of negative potential. In $0.1 \mathrm{M} \mathrm{NaOH}$, the curve shows a marked increase of potential towards positive direction, which indicates that the macroporous silicon electrode surface is oxidized by low concentration of $\mathrm{NaOH}$ solution. It takes about $600 \mathrm{~s}$ to reach the steady-state value about $-1.020 \mathrm{~V}$. In $0.2 \mathrm{M} \mathrm{NaOH}$, the curve shows a slight increase of potential towards positive direction followed by sharp shift in lower values of potential. This demonstrates that the performed oxide layer on the electrode surface will be dissolved after macroporous silicon electrode immersion in $0.2 \mathrm{M} \mathrm{NaOH}$. In 0.5 and $1.0 \mathrm{M} \mathrm{NaOH}$, the curve shows a marked decrease of potential towards negative direction, which shows the corrosion of macroporous silicon in the higher concentration of $\mathrm{NaOH}(>0.5 \mathrm{M})$.

Meanwhile, the open circuit potential-time curves of macroporous silicon in $1.0 \mathrm{M} \mathrm{NaOH}$ with different volume ratios of ethanol $(0 \sim 50 \%)$ at $291 \mathrm{~K}$ are shown in Figure 3. It can be found that the open circuit potential-time curves are obviously influenced by volume ratio of ethanol in $1.0 \mathrm{M}$ $\mathrm{NaOH}$. From Figure 3, the increase of volume ratio of ethanol in $1.0 \mathrm{M} \mathrm{NaOH}$ finally caused a shift in the direction of positive potential. All curves show a marked decrease of potential towards negative direction followed by sharp shift

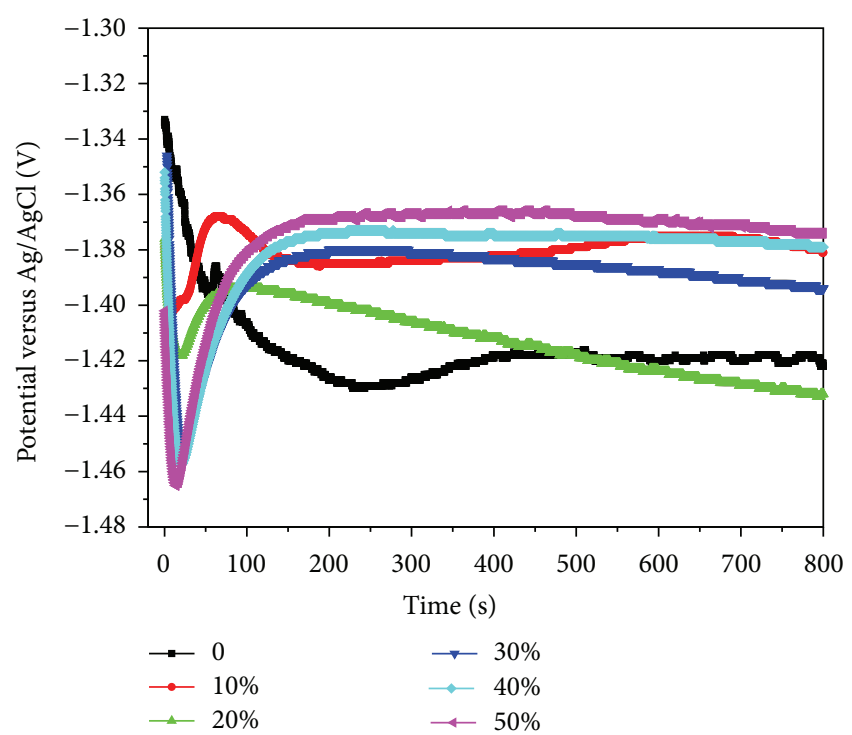

FIGURE 3: Open circuit potential-time curves of macroporous silicon corrosion in $1.0 \mathrm{M} \mathrm{NaOH}$ with different volume ratios of ethanol (0 $50 \%)$.

in higher values of potential after adding ethanol to $\mathrm{NaOH}$. It takes about $100 \mathrm{~s}$ to reach the steady-state values, which indicates that addition of ethanol can shorten the stabilizing time of macroporous silicon in $1.0 \mathrm{M} \mathrm{NaOH}$. This is due to the fact that adding ethanol to $\mathrm{NaOH}$ solution can decrease the surface tension of $\mathrm{NaOH}$ solution and increase wettability to the macroporous silicon sample surface, which are an advantage to the hydrogen gas overflow from the $\mathrm{NaOH}$ solution.

3.3. Linear Polarization Measurements. Figure 4 reveals the typical linear polarization curves of macroporous silicon corrosion in $1.0 \mathrm{M} \mathrm{NaOH}$ in the absence and presence of $30 \%$ ethanol (1.0 M NaOH/EtOH (30\%)) at $291 \mathrm{~K}$. Meanwhile, the linear polarization resistances $\left(R_{p}, \Omega \mathrm{cm}^{2}\right)$ of macroporous silicon corrosion in different concentrations of $\mathrm{NaOH}$ and in $1.0 \mathrm{M} \mathrm{NaOH}$ with various volume ratios of ethanol are shown in Figures 5 and 6, respectively.

The linear polarization resistance of macroporous silicon corrosion in different concentrations of $\mathrm{NaOH}$ solution at $291 \mathrm{~K}$ is shown in Figure 5. This figure illustrates that the linear polarization resistance decreases with the $\mathrm{NaOH}$ concentration increasing, which indicates that the corrosion rate of macroporous silicon in $\mathrm{NaOH}$ solution increases with concentration of $\mathrm{NaOH}$ increasing. This confirms that the higher the $\mathrm{NaOH}$ concentration, the faster the corrosion rate. As seen in Figure 5, the linear polarization resistance sharply decreases with the concentration of $\mathrm{NaOH}$ increasing from $0.1 \mathrm{M}$ to $0.2 \mathrm{M}$. Then, it decreases slightly. This result indicates that the oxidation of macroporous silicon is more obvious in low concentration of $\mathrm{NaOH}$ solution than that in high concentration of $\mathrm{NaOH}$. Additionally, the corrosion and dissolution of macroporous silicon are more obvious in high concentration of $\mathrm{NaOH}$ solution than in low concentration of $\mathrm{NaOH}[20,31]$. 


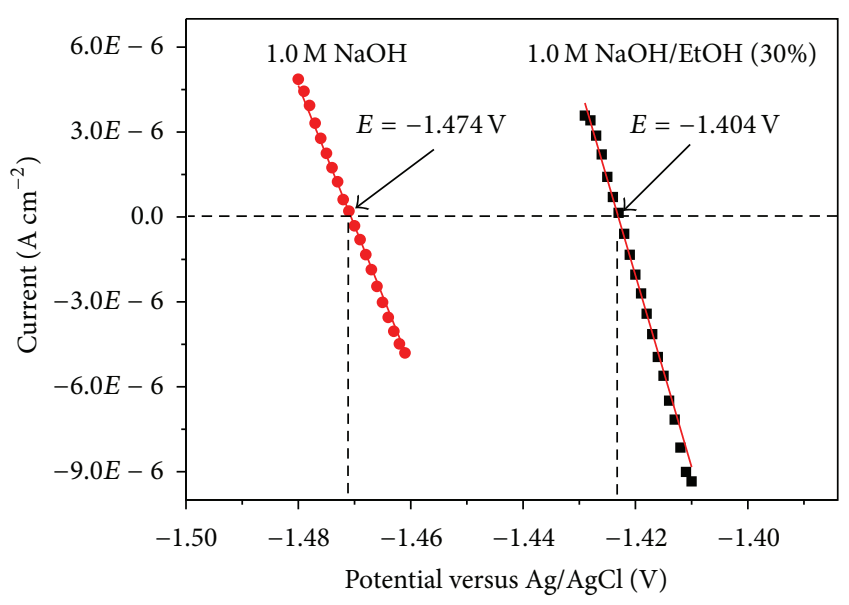

FIgURE 4: Linear polarization curves of macroporous silicon corrosion in $1.0 \mathrm{M} \mathrm{NaOH}$ in the absence and presence of $30 \%$ ethanol at $291 \mathrm{~K}$.

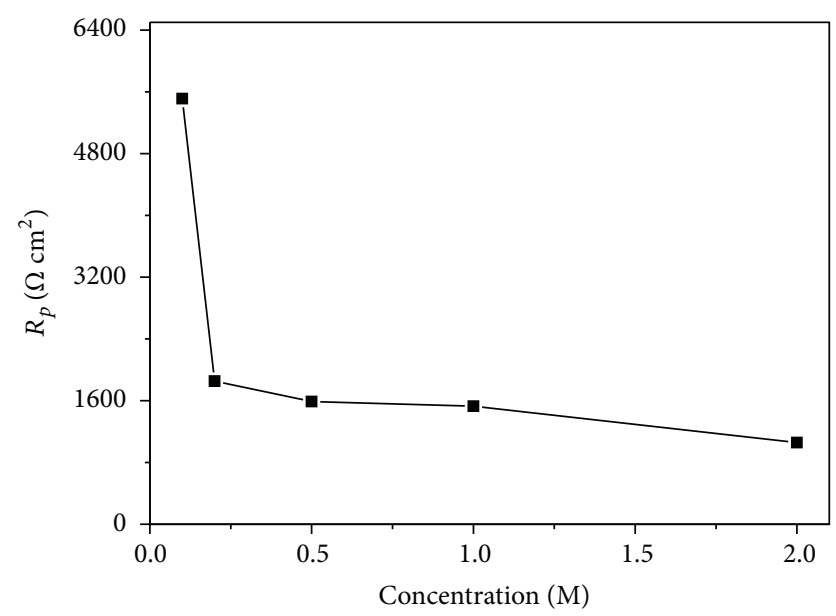

FIGURE 5: Linear polarization resistance of macroporous silicon corrosion in different concentrations of $\mathrm{NaOH}$ solution at $291 \mathrm{~K}$.

The rapid decrease in linear polarization resistance can be attributed to the dissolution/corrosion of macroporous silicon in $\mathrm{NaOH}$ solution, which shows that the corrosion is the predominant process for macroporous silicon in high concentration of $\mathrm{NaOH}$ solution $(>0.1 \mathrm{M})$ [20,31]. Based on (2) and the above fact, it must be mentioned that lower $\mathrm{NaOH}$ concentration can increase the linear polarization resistance and reduce the corrosion rate of macroporous silicon in $\mathrm{NaOH}$ solution, and higher $\mathrm{NaOH}$ concentration can reduce the linear polarization resistance and increase the corrosion rate. Hence,

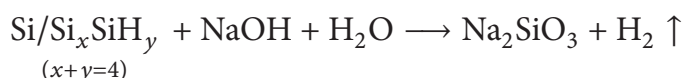

Figure 6 shows the relationship between the linear polarization resistance and the volume ratio of ethanol in $1.0 \mathrm{M}$ $\mathrm{NaOH}$ at $291 \mathrm{~K}$. The value of linear polarization resistance decreases with the volume ratio of ethanol increasing until reaching the minimum value of $1009.5 \Omega \mathrm{cm}^{2}(1.0 \mathrm{M}$
TABLE 1: The potentiodynamic polarization parameters of macroporous silicon corrosion in different concentrations of $\mathrm{NaOH}$ and $1.0 \mathrm{M} \mathrm{NaOH} / \mathrm{EtOH}(0 \sim 50 \%)$.

\begin{tabular}{lcc}
\hline Corrosion solution & $\begin{array}{c}E_{\text {corr }} \text { versus } \\
\mathrm{Ag} / \mathrm{AgCl}(\mathrm{V})\end{array}$ & $I_{\text {corr }}\left(\mathrm{A} \cdot \mathrm{cm}^{-2}\right) \times 10^{-5}$ \\
\hline $0.1 \mathrm{M} \mathrm{NaOH}$ & -1.068 & 0.6182 \\
$0.5 \mathrm{M} \mathrm{NaOH}$ & -1.406 & 1.435 \\
$1.0 \mathrm{M} \mathrm{NaOH}$ & -1.474 & 2.349 \\
$2.0 \mathrm{M} \mathrm{NaOH}$ & -1.488 & 3.216 \\
$1.0 \mathrm{M} \mathrm{NaOH} / \mathrm{EtOH}(30 \%)$ & -1.404 & 4.220 \\
$1.0 \mathrm{M} \mathrm{NaOH} / \mathrm{EtOH}(50 \%)$ & -1.360 & 3.200 \\
\hline
\end{tabular}

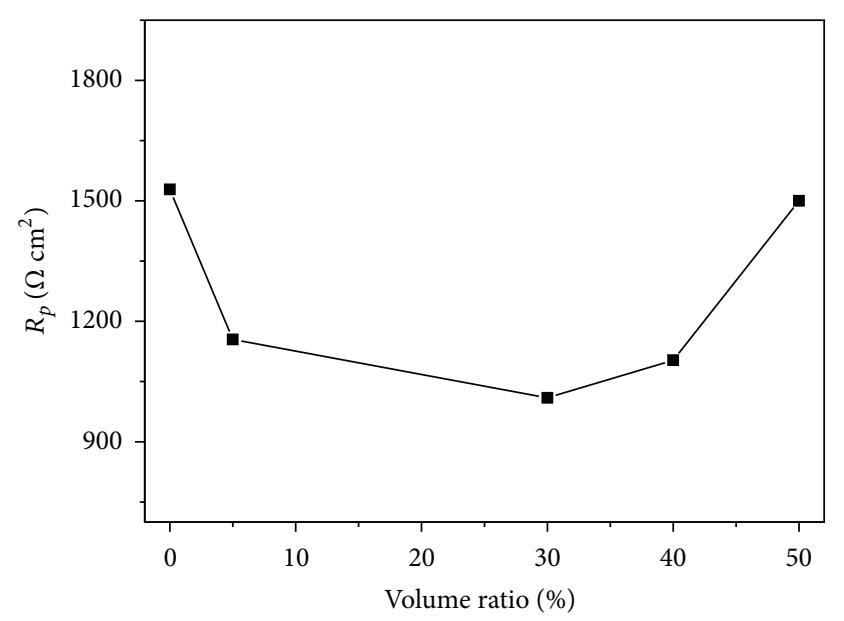

FIGURE 6: Linear polarization resistance of macroporous silicon corrosion in $1.0 \mathrm{M} \mathrm{NaOH}$ with different volume ratios of ethanol at $291 \mathrm{~K}$.

$\mathrm{NaOH} / \mathrm{EtOH}(30 \%))$ and then increases with the volume ratio of ethanol further increasing. The result is well consistent with the fact that the solvent of $\mathrm{H}_{2} \mathrm{O}$ directly participated in the corrosion reaction of macroporous silicon as shown in (2) and the number of $\mathrm{H}_{2} \mathrm{O}$ molecules decreases with the increase of ethanol volume ratio in $1.0 \mathrm{M} \mathrm{NaOH}$. The obvious decrease of linear polarization resistance indicates that the addition of ethanol can lead to the corrosion rate increase, possibly because ethanol can reduce the surface tension of $\mathrm{NaOH}$ solution and increase wettability of macroporous silicon surface [18-20].

3.4. Potentiodynamic Polarization Measurements. At $291 \mathrm{~K}$, the potentiodynamic polarization curves of macroporous silicon in $\mathrm{NaOH}$ solution in the absence and presence of ethanol are shown in Figures 7 and 8. Meanwhile, the electrochemical parameters of corrosion potential $\left(E_{\text {corr }}\right)$ and corrosion current density $\left(I_{\text {corr }}\right)$ for macroporous silicon in $\mathrm{NaOH}$ solution with and without ethanol were listed in Table 1 .

From Figure 7 and Table 1, it can be found that the corrosion potential shifts significantly to more negative potentials and the corrosion current density increases with concentration of $\mathrm{NaOH}$ increasing. The result indicates that 


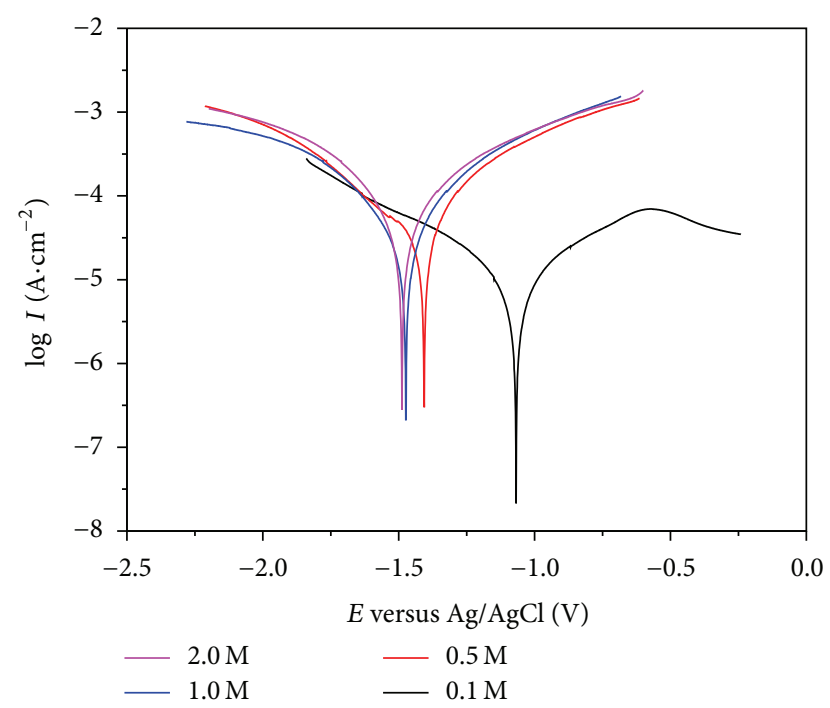

FIGURE 7: Potentiodynamic polarization curves of macroporous silicon corrosion in different concentrations of $\mathrm{NaOH}$ solution.

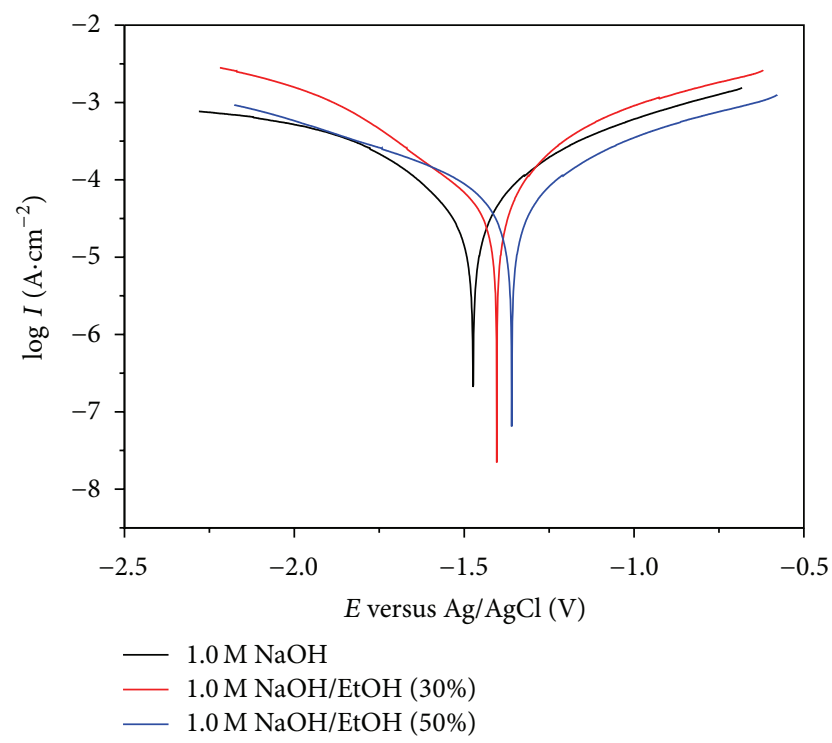

FIGURE 8: Potentiodynamic polarization curves of macroporous silicon corrosion in $1.0 \mathrm{M} \mathrm{NaOH}$ with different volume ratios of ethanol (0 50\%).

$\mathrm{NaOH}$ with high concentration can cause serious corrosion of macroporous silicon.

From Figure 8 and Table 1, it is shown that the addition of ethanol to $1.0 \mathrm{M} \mathrm{NaOH}$ can lead to the corrosion potentials shift in the positive direction and corrosion current density increases. The corrosion potential of macroporous silicon in $1.0 \mathrm{M} \mathrm{NaOH}, 1.0 \mathrm{M} \mathrm{NaOH} / \mathrm{EtOH}$ (30\%), and $1.0 \mathrm{M} \mathrm{NaOH} / \mathrm{EtOH}(50 \%)$ is $-1.474,-1.404$, and $-1.360 \mathrm{~V}$, respectively. The significant increase of corrosion current density for macroporous silicon corrosion also indicates that the addition of ethanol to $\mathrm{NaOH}$ solution can increase the corrosion rate. This may be attributed to the decreasing of surface tension and increasing of wettability. The result obtained from potentiodynamic polarization measurements is in good agreement with linear polarization measurements, where the two different techniques gave the same trend of macroporous silicon corrosion in different concentrations of $\mathrm{NaOH}$ solution in the absence and presence of ethanol. Meanwhile, the obtained result is in good agreement with the weight loss measurements from the reported study $[19,20]$.

3.5. Scanning Electron Microscopy. The scanning electron microscopy (SEM) images of macroporous silicon before and after electrochemical measurements at $291 \mathrm{~K}$ are shown in Figures 9(a)-9(d). These images give a comparison about the surface microstructures on macroporous silicon before corrosion and after corrosion in $1.0 \mathrm{M} \mathrm{NaOH}$ in the absence (c) and presence (d) of 30\% EtOH. The SEM results show that the addition of ethanol to $\mathrm{NaOH}$ has a significant effect on the morphology of macroporous silicon. From Figure 9(a), a few pores and cracks can be seen on the surface of macroporous silicon prepared at the current density of $30 \mathrm{~mA} \mathrm{~cm}^{-2}$ for $30 \mathrm{~min}$. According to the cross-sectional SEM images (Figure 9(b)), it can be found that the thickness of the porous layer is about $135-140 \mu \mathrm{m}$, which confirms the weight loss measurements results obtained from Section 2.2.

Along with the corrosion reaction, as can be seen, the samples ( $a, b)$ are seriously damaged and the porous structure (c, d) is clearly seen after electrochemical measurements in 1.0 $\mathrm{M} \mathrm{NaOH}$ and $1.0 \mathrm{M} \mathrm{NaOH} / \mathrm{EtOH}(30 \%)$, resulting in more pores exposed on the surface of macroporous silicon. The fabricated porous silicon turns out to be macroporous silicon for the average pore diameters of each porous silicon sample of about $1 \mu \mathrm{m}$. Comparing Figure 9(c) with Figure 9(d), the corrosion surface of the macroporous silicon obtained in $1.0 \mathrm{M} \mathrm{NaOH}$ suffers from lack of uniformity with the appearance of heterogeneous pores. On the contrary, the corrosion surface of the macroporous silicon obtained in 1.0 $\mathrm{M} \mathrm{NaOH} / \mathrm{EtOH}(30 \%)$ shows a uniform porous surface.

\section{Conclusions}

All the macroporous silicon samples were fabricated by electrochemical anodization of n-type silicon wafers in the electrolyte solution of $\mathrm{HF}(40 \%): \mathrm{EtOH}(99.5 \%)=1: 1$ with a constant current density of $30 \mathrm{~mA} \mathrm{~cm}^{-2}$ for $30 \mathrm{~min}$. The addition of ethanol to $1.0 \mathrm{M} \mathrm{NaOH}$ can shorten the stabilizing time for macroporous silicon corrosion. The oxidation of macroporous silicon in low concentration of $\mathrm{NaOH}$ solution is more obvious than that in high concentration of $\mathrm{NaOH}$. The corrosion potential shifts significantly to more negative potentials and the corrosion current density increases with concentration of $\mathrm{NaOH}$ increasing. Adding ethanol to $1.0 \mathrm{M}$ $\mathrm{NaOH}$ can lead to the corrosion potentials shift in the positive direction and corrosion current density increase. Macroporous silicon is seriously damaged by $1.0 \mathrm{M} \mathrm{NaOH}$ and $1.0 \mathrm{M} \mathrm{NaOH} / \mathrm{EtOH}(30 \%)$.

\section{Conflict of Interests}

The authors declare that there is no conflict of interests regarding the publication of this paper. 


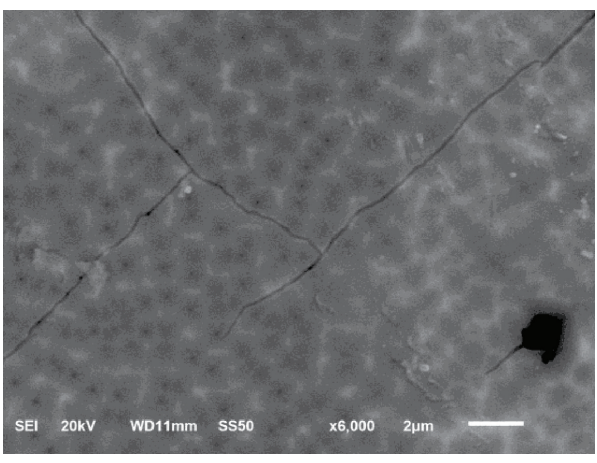

(a)

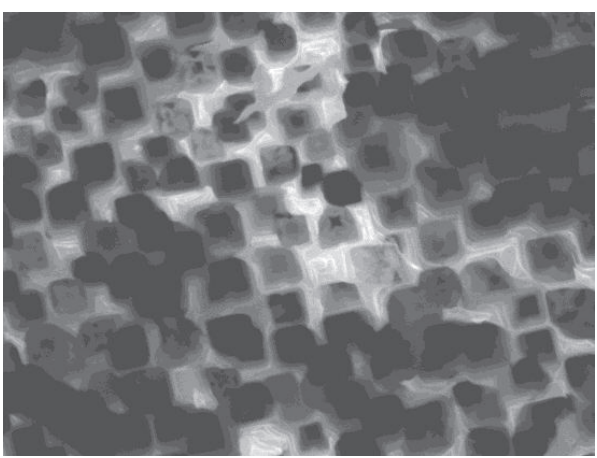

(c)

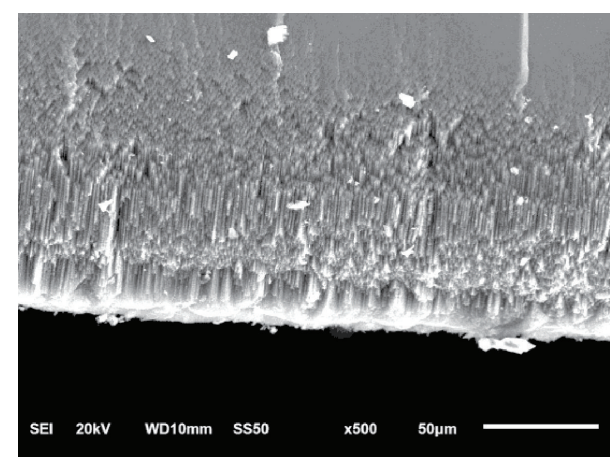

(b)

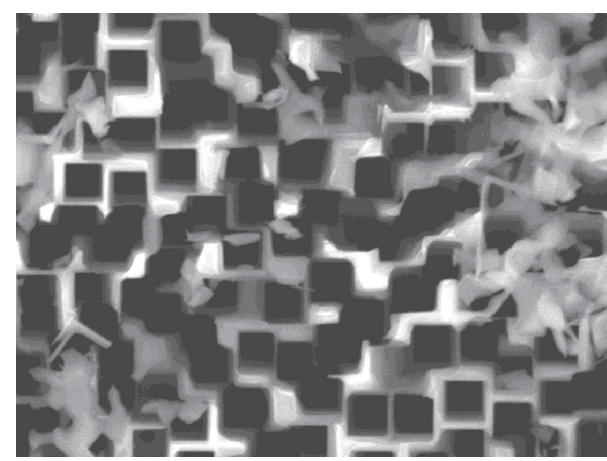

(d)

FIgURE 9: Top view and cross-sectional SEM images of macroporous silicon before corrosion $(\mathrm{a}, \mathrm{b})$ and after corrosion in $1.0 \mathrm{M} \mathrm{NaOH}(\mathrm{c})$ and after corrosion in $1.0 \mathrm{M} \mathrm{NaOH} / \mathrm{EtOH}(30 \%)$ (d) at $291 \mathrm{~K}$.

\section{Acknowledgments}

This project is supported by the Opening Project of Key Laboratory of Green Catalysis of Sichuan Institutes of Higher Education (no. LYJ1503) and the Opening Project of Material Corrosion and Protection Key Laboratory of Sichuan Province (no. 2015CL09).

\section{References}

[1] A. Uhlir, "Electrolytic shaping of germanium and silicon," Bell System Technical Journal, vol. 35, no. 2, pp. 333-347, 1956.

[2] L. T. Canham, "Silicon quantum wire array fabrication by electrochemical and chemical dissolution of wafers," Applied Physics Letters, vol. 57, no. 10, pp. 1046-1048, 1990.

[3] W. Sun, J. E. Puzas, T.-J. Sheu, X. Liu, and P. M. Fauchet, "Nanoto microscale porous silicon as a cell interface for bone-tissue engineering," Advanced Materials, vol. 19, no. 7, pp. 921-924, 2007.

[4] F. Cunin, T. A. Schmedake, J. R. Link et al., "Biomolecular screening with encoded porous-silicon photonic crystals," Nature Materials, vol. 1, no. 1, pp. 39-41, 2002.

[5] A. Tzur-Balter, A. Gilert, N. Massad-Ivanir, and E. Segal, "Engineering porous silicon nanostructures as tunable carriers for mitoxantrone dihydrochloride," Acta Biomaterialia, vol. 9, no. 4, pp. 6208-6217, 2013.

[6] V. S.-Y. Lin, K. Motesharei, K.-P. S. Dancil, M. J. Sailor, and M. R. Ghadiri, "A porous silicon-based optical interferometric biosensor," Science, vol. 278, no. 5339, pp. 840-843, 1997.
[7] N. H. Maniya, S. R. Patel, and Z. V. P. Murthy, "Study on surface chemistry and particle size of porous silicon prepared by electrochemical etching," Materials Research Bulletin, vol. 57, pp. 6-12, 2014.

[8] I. I. Ivanov, V. A. Skryshevsky, T. Nychyporuk et al., "Study on surface chemistry and particle size of porous silicon prepared by electrochemical etching," Renewable Energy, vol. 55, pp. 79-84, 2013.

[9] C. Zhan, P. K. Chu, D. Ren et al., "Release of hydrogen during transformation from porous silicon to silicon oxide at normal temperature," International Journal of Hydrogen Energy, vol. 36, no. 7, pp. 4513-4517, 2011.

[10] H. Y. Zhang, Z. H. Jia, X. Y. Lv et al., "Porous silicon optical microcavity biosensor on silicon-on-insulator wafer for sensitive DNA detection," Biosensors and Bioelectronics, vol. 44, no. 1, pp. 89-94, 2013.

[11] J. D. Benjamin, J. M. Keen, A. G. Cullis, B. Innes, and N. G. Chew, "Large area, uniform silicon-on-insulator using a buried layer of oxidized porous silicon," Applied Physics Letters, vol. 49, no. 12, pp. 716-718, 1986.

[12] G. Toker, R. Sagi, S. Bar-Nachum, and M. Asscher, "Highly efficient photoinduced desorption of $\mathrm{N}_{2} \mathrm{O}$ and $\mathrm{CO}$ from porous silicon," The Journal of Chemical Physics, vol. 138, no. 4, Article ID 044710, 2013.

[13] W. Lang, P. Steiner, A. Richter, K. Marusczyk, G. Weimann, and H. Sandmaier, "Application of porous silicon as a sacrificial layer," Sensors and Actuators A. Physical, vol. 43, no. 1-3, pp. 239-242, 1994.

[14] K. Rahmoun, H. I. Faraoun, G. Bassou, C. Mathieu, and N. E. C. Sari, "Determination of mechanical properties of porous silicon 
with image analysis and finite element," Physics Procedia, vol. 55, pp. 390-395, 2014.

[15] J. Kanungo, S. Maji, H. Saha, and S. Basu, "Chemical surface modification of porous silicon with palladium and characterizations," Materials Science and Engineering B: Solid-State Materials for Advanced Technology, vol. 167, no. 2, pp. 91-96, 2010.

[16] G. L. Liu, P. Y. Dai, Y. Z. Wang, J. F. Yang, and Y. B. Zhang, "Fabrication of wood-like porous silicon carbide ceramics without templates," Journal of the European Ceramic Society, vol. 31, no. 5, pp. 847-854, 2011.

[17] Y. Q. Qu, X. Zhong, Y. J. Li, L. Liao, Y. Huang, and X. F. Duan, "Photocatalytic properties of porous silicon nanowires," Journal of Materials Chemistry, vol. 20, no. 18, pp. 3590-3594, 2010.

[18] C. Lai, X.-M. Li, L.-K. Zou et al., "Corrosion of porous silicon in tetramethylammonium hydroxide solution," Corrosion Science, vol. 85, pp. 471-476, 2014.

[19] C. Lai, X. M. Li, Z. Xiang, Z. Tao, D. X. Zhang, and W. J. Yang, "Study on corrosion of porous silicon in $\mathrm{KOH}$ and $\mathrm{NaOH}$ solution," Corrosion Engineering Science and Technology, vol. 49, no. 5, pp. 386-389, 2014.

[20] C. Lai, X. M. Li, D. X. Zhang, Z. Xiang, W. J. Yang, and X. G. Guo, "Fabrication and corrosion behavior of fresh porous silicon in sodium hydroxide solution," Materials Chemistry and Physics, vol. 144, no. 3, pp. 355-360, 2014.

[21] F. A. Harraz, A. M. Salem, B. A. Mohamed, A. Kandil, and I. A. Ibrahim, "Electrochemically deposited cobalt/platinum (Co/Pt) film into porous silicon: structural investigation and magnetic properties," Applied Surface Science, vol. 264, pp. 391398, 2013.

[22] A. G. Cullis, L. T. Canham, and P. D. J. Calcott, "The structural and luminescence properties of porous silicon," Journal of Applied Physics, vol. 82, no. 3, pp. 909-965, 1997.

[23] F. A. Harraz, T. Sakka, and Y. H. Ogata, "A comparative electrochemical study of iron deposition onto n- and p-type porous silicon prepared from lightly doped substrates," Electrochimica Acta, vol. 50, no. 27, pp. 5340-5348, 2005.

[24] V. Lehmann and U. Gösele, "Porous silicon formation: a quantum wire effect," Applied Physics Letters, vol. 58, no. 8, pp. 856-858, 1991.

[25] S. Dhanekar and S. Jain, "Porous silicon biosensor: current status," Biosensors and Bioelectronics, vol. 41, no. 1, pp. 54-64, 2013.

[26] C. Lai, X. M. Li, C. L. Liu et al., "Improvement in gravimetric measurement for determining the porosity and thickness of porous silicon using an optimized solution," Materials Science in Semiconductor Processing, vol. 26, no. 1, pp. 501-505, 2014.

[27] C. Lai and Z. Xiang, "Investigation the effect of porosity on corrosion of macroporous silicon in $1.0 \mathrm{M}$ sodium hydroxide solution using weight loss measurements, electrochemical methods and scanning electron microscope," Corrosion Science, 2015.

[28] E. J. Anglin, L. Cheng, W. R. Freeman, and M. J. Sailor, "Porous silicon in drug delivery devices and materials," Advanced Drug Delivery Reviews, vol. 60, no. 11, pp. 1266-1277, 2008.

[29] M. J. Sailor, Porous Silicon in Practice, Wiley-VCH, Gilman City, Mo, USA, 2012.

[30] J. Riikonen, M. Salomäki, J. van Wonderen et al., "Surface chemistry, reactivity, and pore structure of porous silicon oxidized by various methods," Langmuir, vol. 28, no. 28, pp. 10573-10583, 2012.
[31] Y. Mo, A. S. Ren, J. F. Mao et al., "Photoluminescence of oxidized porous silicon treated by sodium borohydride aqueous solution," Materials Letters, vol. 75, pp. 115-117, 2012. 

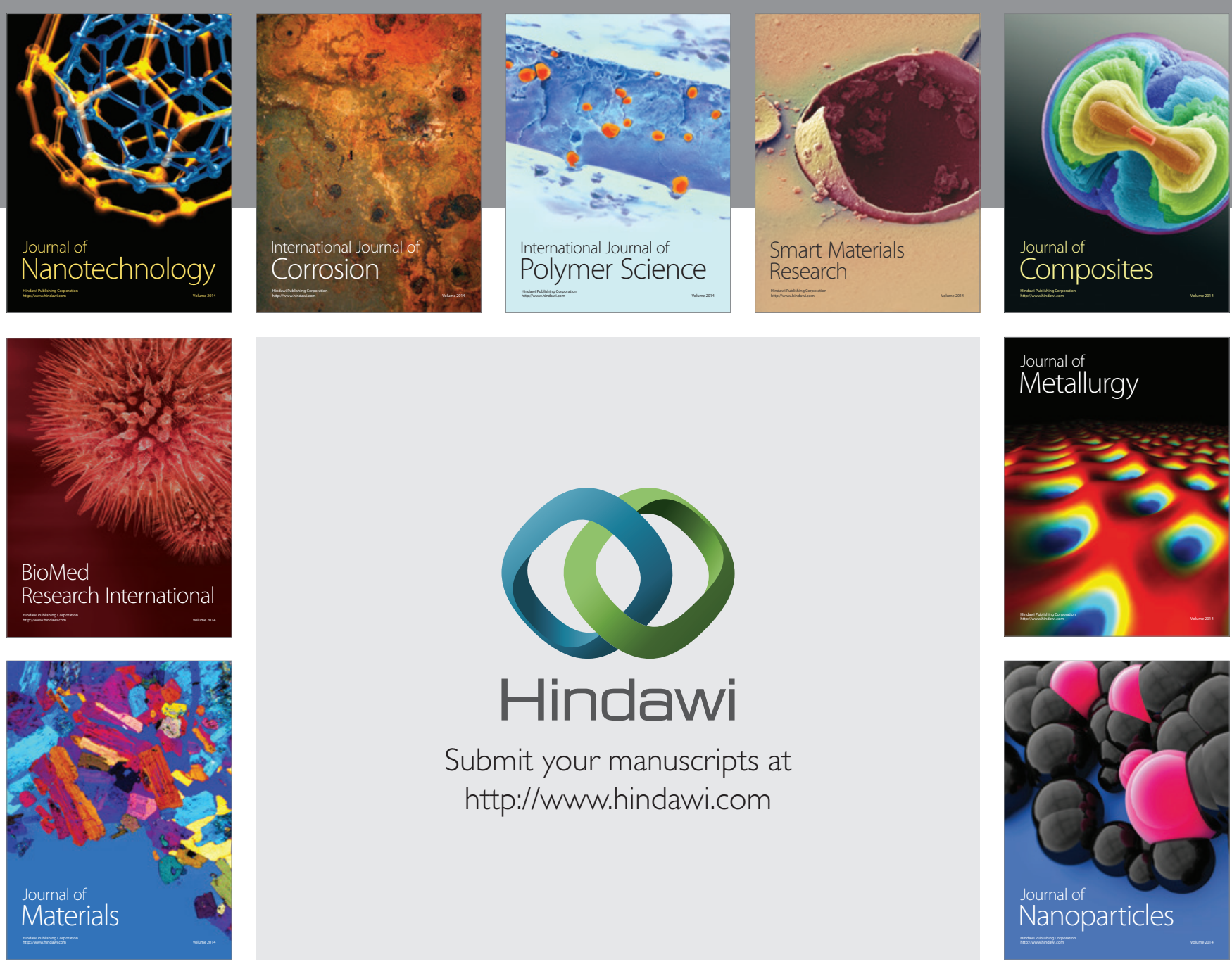

Submit your manuscripts at http://www.hindawi.com
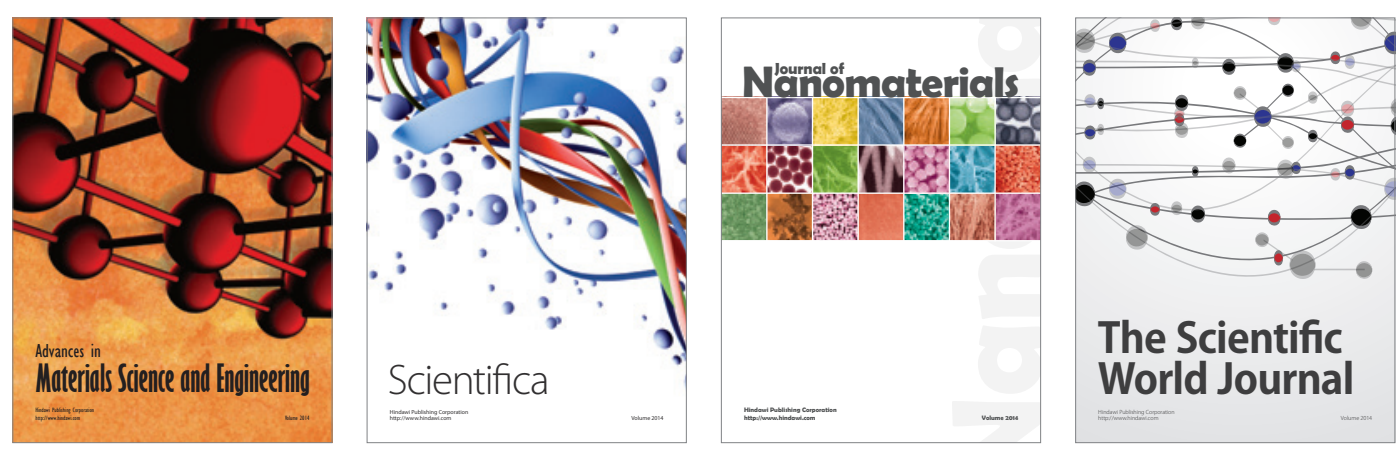

\section{The Scientific World Journal}
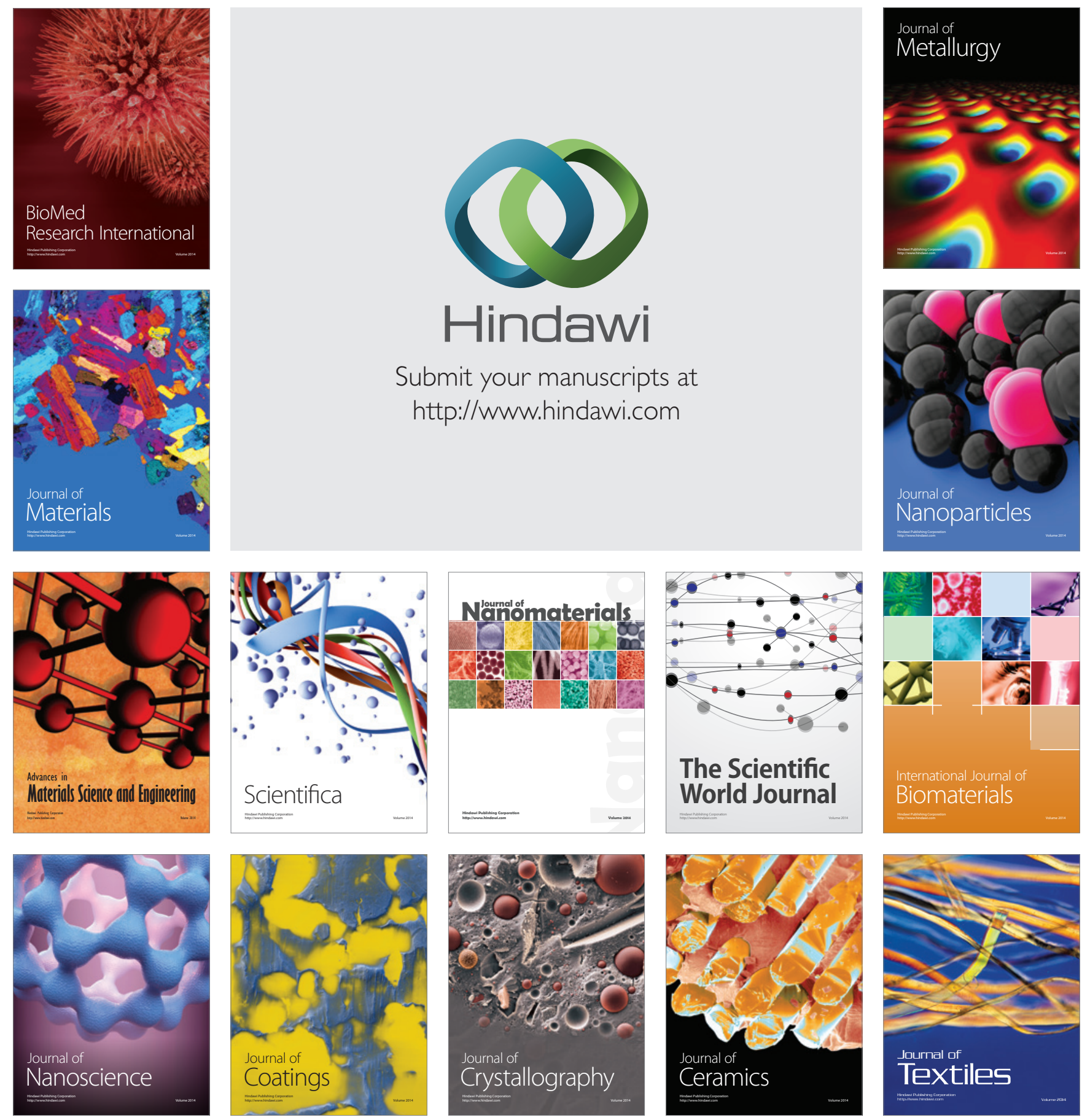